\title{
Tisosa: Un establecimiento suburbano de Segisamo (Sasamón, Burgos)
}

\section{Tisosa: A suburban site in the surroundings of Segisamo (Sasamón, Burgos)}

\author{
Jesús García Sánchez \\ Arqueólogo \\ Miguel Cisneros Cunchillos \\ Universidad de Cantabria
}

\section{RESUMEN}

Los trabajos de prospección y de fotointerpretación han permitido localizar un nuevo yacimiento en el entorno de Sasamón, que pudo estar relacionado con la fundación de la ciudad y perduró en el tiempo como indica la presencia de terra sigillata hispánica altoimperial y terra sigillata hispánica tardía. El yacimiento representa un elemento novedoso dentro del proceso de ocupación del espacio en la región, según una estrategia claramente romana. En este trabajo, además de aspectos metodológicos, se aborda el estudio de los materiales, planteando algunas hipótesis sobre su finalidad y cronología.

\section{SUMMARY}

Pedological surveys and oblique aerial image interpretation have led us to the location of a new site in the suburban area of Sasamón. Its original function may have been related with to the foundation of the city of Segisamo and afterwards lasted throughout several centuries according to the presence of Late Hispanic sigillata. The site represents new findings on the Roman settlement pattern in the area. In addition to methodological issues, this paper addresses the study of the material culture in order to propose hypothesis about function and chronology.

PALABRAS CLAVES: prospección intra-site, fotografía aérea, cerámica romana, asentamiento rural, Hispania Citerior.

KEY WORDS: intra-site survey, aerial photography, Roman pottery, rural settlement, Hispania Citerior.

\section{INTRODUCCIÓN ${ }^{1}$}

El enclave romano de Segisamo es conocido por la importancia que desempeñó en las guerras contra

${ }^{1}$ Las prospecciones incluidas en este trabajo se realizaron en los años 2009 (57/09-BU), 2010 (27/10-BU), 2011 (21/11BU) y 2012 (14/12-BU), siendo financiadas por la Junta de cántabros y astures, al ubicarse en él, el campamento desde donde Augusto dirigió el conflicto, y por la posterior organización del territorio en este sector de la Meseta norte como puede observarse en los hitos terminales que separan sus campos de los pertenecientes a los Iuliobrigenses (Retortillo, Reinosa, Cantabria) y de los prata de la legio IIII Macedonica asentada en Pisoraca (Herrera de Pisuerga, Palencia) (García y Bellido et alii 1970; Crespo y Alonso 2000; Cortés 2009; Fernández Vega et alii 2012).

La historiografía sobre el núcleo romano ha tenido siempre en cuenta la existencia de un asentamiento de la Edad de Hierro y también algunos enclaves supuestamente de función militar, que actuarían como vínculos temporales entre la desaparición del yacimiento prerromano y el establecimiento definitivo de la ciudad romana. Aquel ha despertado el interés por relacionarlo con alguna ciudad mencionada por Plinio o Ptolomeo, especulándose con diferentes emplazamientos. Para Abásolo (1998) este enclave se localiza en las laderas del castillo de Castrojeriz (Burgos), dada la entidad de los restos celtibéricos encontrados en un vertedero. Rodríguez Colmenero

Castilla y León, el Ayuntamiento de Villadiego y el Grupo de Acción Local Adeco Camino. El programa de fotografía aérea se ha realizado gracias a las becas concedidas a $\mathrm{J}$. García Sánchez en los años 2011 y 2012 dentro del programa de Becas para Jóvenes Excelentes de la Obra Social de Caja Burgos y la Fundación Gutiérrez Manrique. Agradecemos las opiniones que sobre diferentes aspectos nos han aportado María del Carmen Aguarod, Miguel Beltrán, Macarena Bustamante, Juan Paz, Fernando Pérez Rodríguez, Javier Pérez Rodríguez, José Luis Ramírez, María Luisa Ramos, José David Sacristán de Lama, Desiderio Vaquerizo y Darío Vidal durante la investigación y la publicación. 
(1979) por su parte planteó la hipótesis de que la Segisama turmoga se encontrase bajo la localidad de Villasandino (Burgos). Sin embargo, Sacristán de Lama (2007: 73) considera que la Segisamon (sic) prerromana se ubicaría en un amplio cerro testigo de la localidad de Olmillos de Sasamón, a escasos 3 km del actual Sasamón (Fig. 1).

Este último se trata de un promontorio, asociado al topónimo Castarreño, desgajado del páramo calcáreo o páramo del Arlanzón y por tanto diferenciado del paisaje de campiña predominante en la zona, que se corresponde al tipo de poblamiento D1 de Llanos (1974). Tradicionalmente, se ha defendido que su ocupación comprendería la totalidad de la colina, aproximadamente unas 26 ha, y se le ha presupuesto una escasa densidad de ocupación, aunque no se han realizado actividades arqueológicas más allá de la prospección (García Sánchez y Cisneros 2013: 298). Su posición topográfica es indicativa por sí misma de la naturaleza defensiva del asentamiento, ya que domina un amplio territorio del páramo.

En cuanto a su territorio productivo teórico podemos realizar varias consideraciones: el análisis de captación de recursos restringido a la isocrona de treinta minutos da como resultado un territorio de explotación centrado en el ámbito superior del cerro amesetado, mientras que la isocrona de sesenta minutos comprende un ámbito más extenso en el que se encuentran zonas de regadío y secano, especialmente al oeste del yacimiento, en la confluencia de los ríos Odra y Brullés (García Sánchez 2009).

La identificación del núcleo romano plantea menos problemas, fundamentalmente debido a la presencia de varios miliarios en el entorno de la vía De Hispania in Italia (Didierjean y Abásolo 2007: 413- 419) y al epígrafe, aparecido en Villasidro (Burgos), que delimita los prata militaris de la legio IIII con el territorio de los Segisamonenses. Aun así son dos las controversias que plantea la arqueología clásica. La primera se refiere a la discusión sobre el lugar de ubicación del emplazamiento militar, en ocasiones situado bajo el solar de la propia Sasamón (Abásolo 1975) o en el cercano Cerro del Otero. A ello, se pueden añadir las referencias de Floro (II, 33, 48) y Orosio (VI, 21, 3) al campamento de las legiones de Augusto apud Segisama, sin que por el momento se hayan localizado estructuras relacionadas con dicho asentamiento militar.

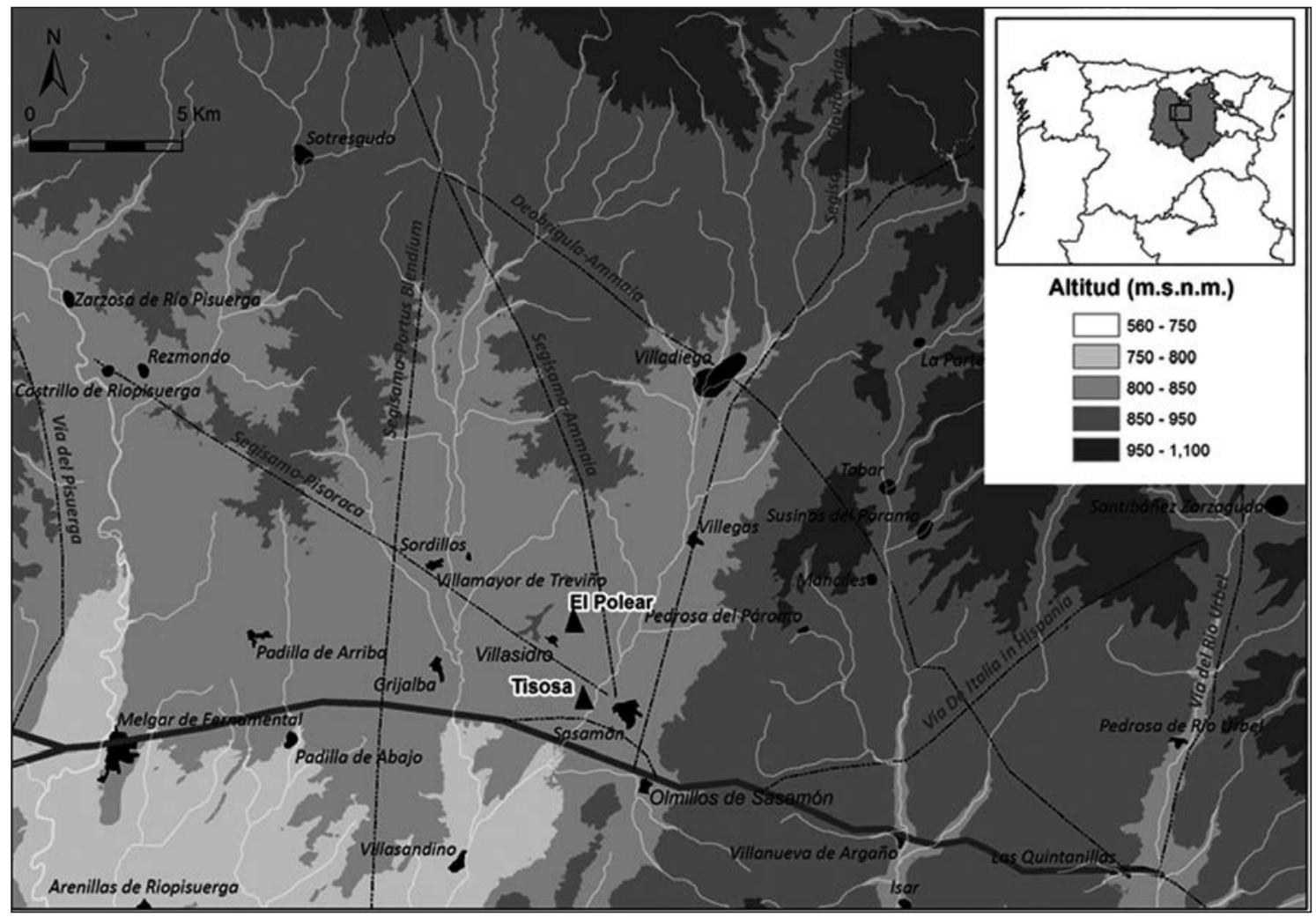

Figura 1. Mapa ubicación Olmillos de Sasamón, Sasamón y vías romanas (J. García Sánchez). 
En segundo lugar, es recurrente la confusión entre Segisamo y Segisama Iulia, ya que ambos nombres aparecen en la obra de Plinio, lo que ha originado opiniones divergentes en el debate historiográfico, que se pueden agrupar en dos corrientes: una, distingue los dos núcleos, donde Segisamo sería Sasamón y Segisama Iulia una posible ciudad vaccea (diferente del enclave turmogo), probablemente en la actual Castrojeriz (Núñez y Churchin 2005: 564-567). Otra identifica ambas ciudades con la actual Sasamón (García Merino 1975: 230; Pérez Centeno 1999: 172-174).

En el pasado, Abásolo y García (1993) realizaron excavaciones en el centro del núcleo urbano, donde documentaron estructuras altoimperiales y niveles de fundación, vinculando los datos obtenidos a las referencias epigráficas antes mencionadas y zanjando, a su entender, la cuestión de la localización de la ciudad romana, a la que previamente uno de ellos le había asignado un origen militar, a partir de la interpretación campamental del actual entramado de calles (Abásolo 1975). Como señala el primero de dichos investigadores (Abásolo 1998: 585), la aparición de Sasamón en la memoria histórica está ligada a la presencia romana en las tierras de la Celtiberia y del Norte de Hispania con motivo de las guerras cántabras. Es evidente que la identificación de una población con un topónimo mayor aparecido en las fuentes clásicas pesa en la historiografía de tal lugar.

Los estudios más recientes se enfocan a un ámbito de trabajo completamente diferente. Así, Moreno lo hace hacia las vías romanas y los acueductos que suministraban agua a la ciudad desde las fuentes cercanas (Moreno 2004), mientras que otros estudiosos utilizan la fotografía aérea, en especial para aportar nuevos datos sobre el paisaje urbano y periurbano del Sasamón romano y detectar la vía aquitana a su paso por la población (Didierjean y Abásolo 2007).

Nuestro interés en esta zona del páramo burgalés es consecuencia de una serie de trabajos de prospección extensiva, iniciados en 2006, con objeto de estudiar la evolución del territorio en el sector central de la Cordillera Cantábrica entre la Edad del Hierro y la época romana. Estos trabajos complementaban los de prospección y excavación iniciados en 1997 en la zona arqueológica de La Ulaña (Cisneros y López Noriega 2004; 2005; Cisneros 2008). La propia dinámica de la investigación nos llevó a un replanteamiento de la metodología inicial (García Sánchez 2009; 2012), trascendiendo los asentamientos propiamente dichos y centrándonos en la investigación del territorio y su explotación, pero manteniendo las mismas consideraciones teóricas que nos llevaron en un primer momento a plantear el análisis de la captación de recursos: la explotación de los terrenos más cercanos al lugar de habitación, disminuyendo su intensidad conforme aumenta la distancia a los campos de cultivo. Asumimos como hipótesis de partida que la explotación del campo, como fenómeno cultural, también puede dejar huella en el registro arqueológico e incluso planteamos la posibilidad de la existencia de una continua dispersión de materiales como resultado del abonado de los campos o como solución para desprenderse de basura doméstica.

Con ello pretendíamos estudiar el cambio cultural en la gestión y explotación del paisaje agrícola a través del registro material y, al mismo tiempo, evaluar la viabilidad de la hipótesis del abonado o manure hypothesis, formulada por Bintliff y Snodgrass (1988) para el estudio de dispersiones de material a escala regional en sus prospecciones en Beocia (Grecia) a partir de reflexiones previas de Foley (1981). Esta hipótesis, que tanto debate ha suscitado en todo el Mediterráneo, como marcador de actividad antrópica en el paisaje y sobre la que se puede encontrar una discusión propia (García-Sánchez y Cisneros 2013: 295), plantea que la actividad humana en el paisaje puede rastrearse mediante la prospección de un registro material con un origen no asociado a los restos de la destrucción de asentamientos, sino a la aportación de materiales de abono orgánico mezclado con basura doméstica en los campos de cultivo. A este simple principio se le suele aplicar una norma de economía del esfuerzo por lo que se esperaría grandes concentraciones de material off-site en el entorno de los núcleos habitados, decreciendo en intensidad conforme aumentase la distancia a estos. Además, la adición de materiales cerámicos a los campos de cultivo puede ser interpretado como un acto consciente, ya que presenta beneficios para los cultivos preindustriales, dado que la cerámica altera la textura y porosidad del suelo incrementando la vida microbiótica que transforma los minerales en nutrientes para los cultivos (Fuentes 1989). Recientemente Forbes (2013) ha añadido algunas consideraciones desde el punto de vista de la etnografía sobre el tratamiento de los residuos domésticos inorgánicos que forman parte de abono en Methana (Grecia), estableciendo una curiosa analogía con los materiales modernos que acaban en los huertos domésticos de Inglaterra.

Aunque en el transcurso de la investigación esta ha ido reorientándose, es evidente que nuestro objetivo es aproximarnos a los paisajes de la Edad del Hierro y de época romana, entendiéndolos como un elemento construido culturalmente y sobre el que se pueden registrar materialmente los procesos de explotación y uso acontecidos en el pasado; es decir, entendiéndolos como un marco de relaciones entre el ser humano y el medio físico. Idea de la que surge la concepción 


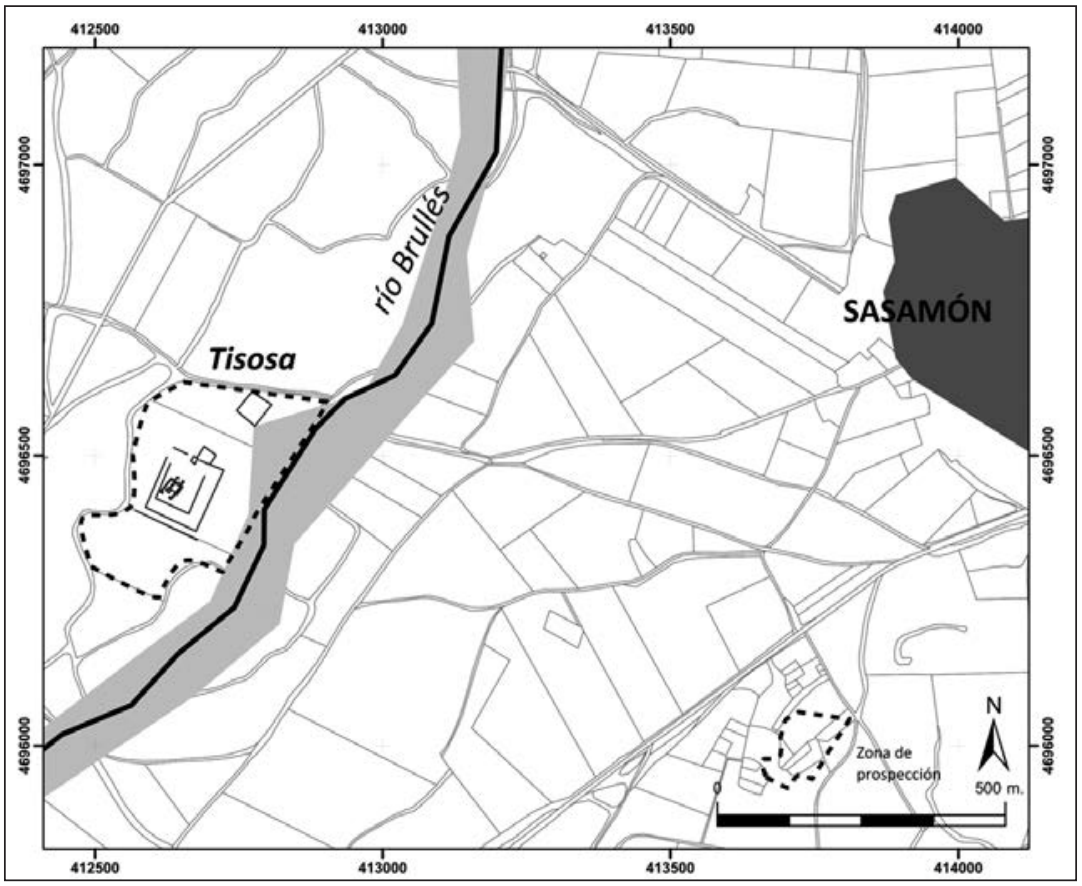

Figura 2. Mapa de la ubicación del yacimiento de Tisosa (J. García Sánchez).

de taskscape (Ingold 1993) o paisajes formados por las actividades del hombre a lo largo del tiempo. Por ello, planteamos una documentación de espacios de actividad desligados de los asentamientos, una prospección orientada a la documentación del registro off-site (Foley 1981; Bintliff 2000) en los alrededores de la actual Sasamón, y del enclave protohistórico, con objeto no solo de intentar reconocer la explotación del medio en dichas épocas, sino también de poder examinar la formación del registro arqueológico de superficie en el marco de la Arqueología del Paisaje, considerando a esta como un "constructo de base" útil en la investigación sobre cómo se han construido los paisajes a lo largo de las ocupaciones humanas (Anschuetz et alii 2001).

Esta prospección orientada off-site se desarrolló durante los años 2009 y 2010. Inicialmente se prospectó una extensión de unas 900 ha en el noroeste, oeste y suroeste de Sasamón, así como en el castro de Olmillos y sus laderas. Esta zona ya se encontraba incluida en el inventario arqueológico publicado por Abásolo (1978), en el que se recogen las referencias anteriores, así como algunas proporcionadas por informantes locales y ha sido objeto de diversas actualizaciones, como se puede comprobar en el Inventario Arqueológico de Castilla y León, pero el denominador común de todos estos trabajos ha sido su interés por los lugares de habitación.
No era, por tanto, nuestro objetivo localizar nuevos asentamientos, sino documentar la continuidad del material arqueológico en superficie. Sin embargo, en el transcurso de la prospección se localizó una concentración de material constructivo y algunos otros elementos cerámicos cuyo origen parecía estar en el derrumbe de un edificio de cronología romana. Dicho yacimiento ubicado en las inmediaciones de Sasamón se localiza en el pago de Tisosa, un topónimo que no se utiliza en la actualidad, pero que sí aparece reflejado en la cartografía catastral (Fig. 2).

\section{DESCRIPCIÓN Y METODOLOGÍA}

El yacimiento se encuentra en la orilla izquierda del río Brullés, a la altura del lugar denominado Carremelgar, que hasta hace varias décadas ocupaba un puente, en la actualidad abandonado, en el camino entre Sasamón y Melgar de Fernamental (Burgos). Remontando el cauce deberíamos encontrar el paso de la vía secundaria entre Segisamo y Pisoraca, actualmente perdido, aunque permanece el puente y el camino medieval, que en ocasiones utilizan el empedrado romano, todavía conservado en los linderos de la orilla izquierda del río. A ambos lados de este se ha podido documentar el trazado de la vía romana mediante fotografía aérea. Moreno (2001), Didierjean 


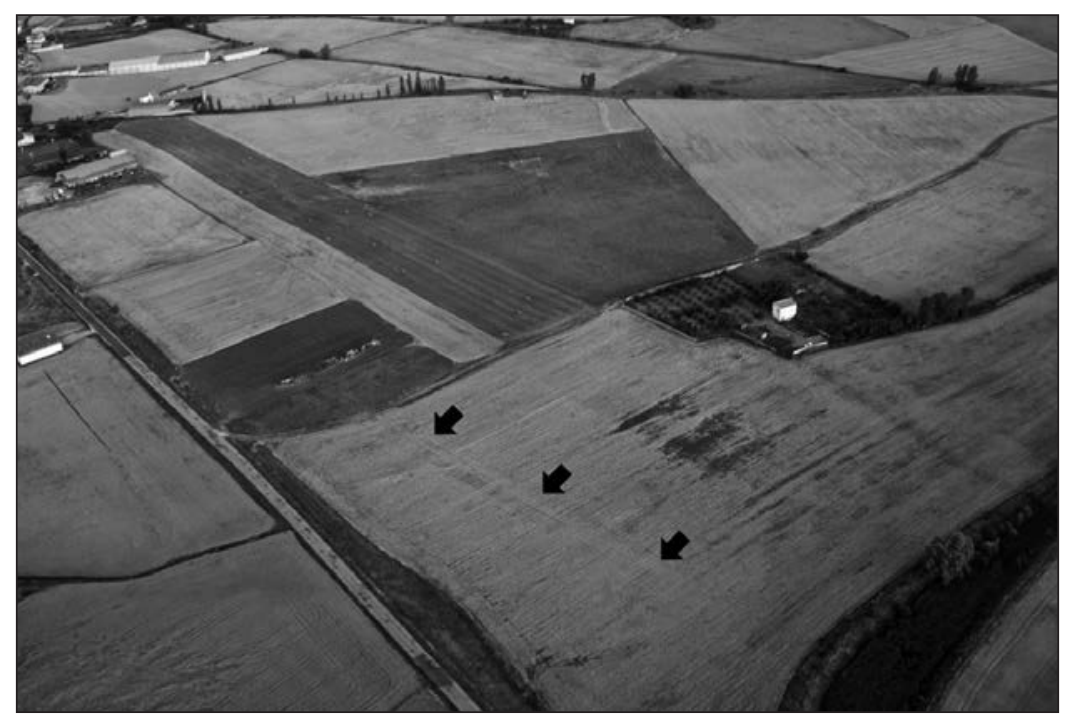

Figura 3. Fotografía aérea de la vía Segisamo-Pisoraca a su paso por el río Brullés (J. García Sánchez).

y Abásolo (2007) y nosotros mismos hemos captado imágenes donde se aprecian de forma indudable las alteraciones en el cultivo que indican la presencia soterrada de una obra constructiva, una vía romana (Fig. 3).

Las parcelas que albergan el yacimiento carecen de relieves destacados, conformando un terreno llano, en consonancia con el marco regional de la vega del Brullés, dedicado a la agricultura de secano, lo que ofrece un contexto de trabajo extraordinario para la prospección y la fotografía aérea. El análisis de ésta permitió conocer la evolución del paisaje en el entorno del yacimiento, los cambios parcelarios y la modificación del cauce del río, que atravesaba el paraje, formando un codo. En la actualidad, se encuentra encajado entre taludes ligeramente al este de su posición original para impedir su desbordamiento. El lecho del antiguo cauce puede reconocerse gracias a una capa superficial de gravas y cantos. En la fotografía infrarroja esta zona aparece perfectamente diferenciada por acumular aún mayor humedad y por tanto reflectancia en el espectro infrarrojo. El resto de las parcelas tienen una matriz arenosa-arcillosa y limitan al oeste con el arroyo de Zuel y algunos canales de regadío construidos junto a este pequeño cauce (Fig. 4).

Desde un primer momento se hizo necesario un planteamiento metodológico que se adecuase a la escala y contexto, abandonando la aproximación off-site. La estrategia elegida fue la prospección Código Por Material (CPM en adelante), que realizamos en el año 2010, cuya metodología, que hemos descrito en extenso en otros trabajos (García Sánchez 2013), se caracteriza por permitirnos comparar los resultados con otras fuentes de información, como los fotogramas del Plan Nacional de Ortofotografía Aérea (PNOA), el vuelo americano de 1956 o nuestros propios vuelos para la realización de fotografía aérea oblicua, que se han desarrollado desde mayo de 2011. El principal objetivo de esta metodología de prospección CPM es generar información de gran resolución de las distribuciones de material arqueológico en superficie. Para ello se emplean dispositivos GPS para geo-localizar cada uno de los artefactos encontrados. Los prospectores cuentan con una lista predefinida de los tipos más habituales de material arqueológico romano, lo que resulta sencillo de establecer en grandes grupos funcionales, debido a su gran tasa de producción y su grado de estandarización (Peña 2007). Cada tipo de material se identifica con un código que acompaña al número de registro en los dispositivos GPS. El resultado final es una nube de puntos, que representa la distribución de material en superficie, que puede filtrarse por tipos de material y analizarse de acuerdo a diversas técnicas geoestadísticas (Fig. 5).

Mediante esta metodología no pretendemos sugerir que las distribuciones de material arqueológico representan directamente lugares funcionales, más bien intentamos superar la tradicional dependencia de geometrías de agregación de resultados de prospección, que introduce sesgos en la representación y análisis de los datos, y valorar los beneficios y carencias de este tipo de aproximación al registro material. Esta problemática, conocida como MAUP (Modifiable Area Unit Problem) ha sido abordada desde la geoestadística y en las últimas décadas 


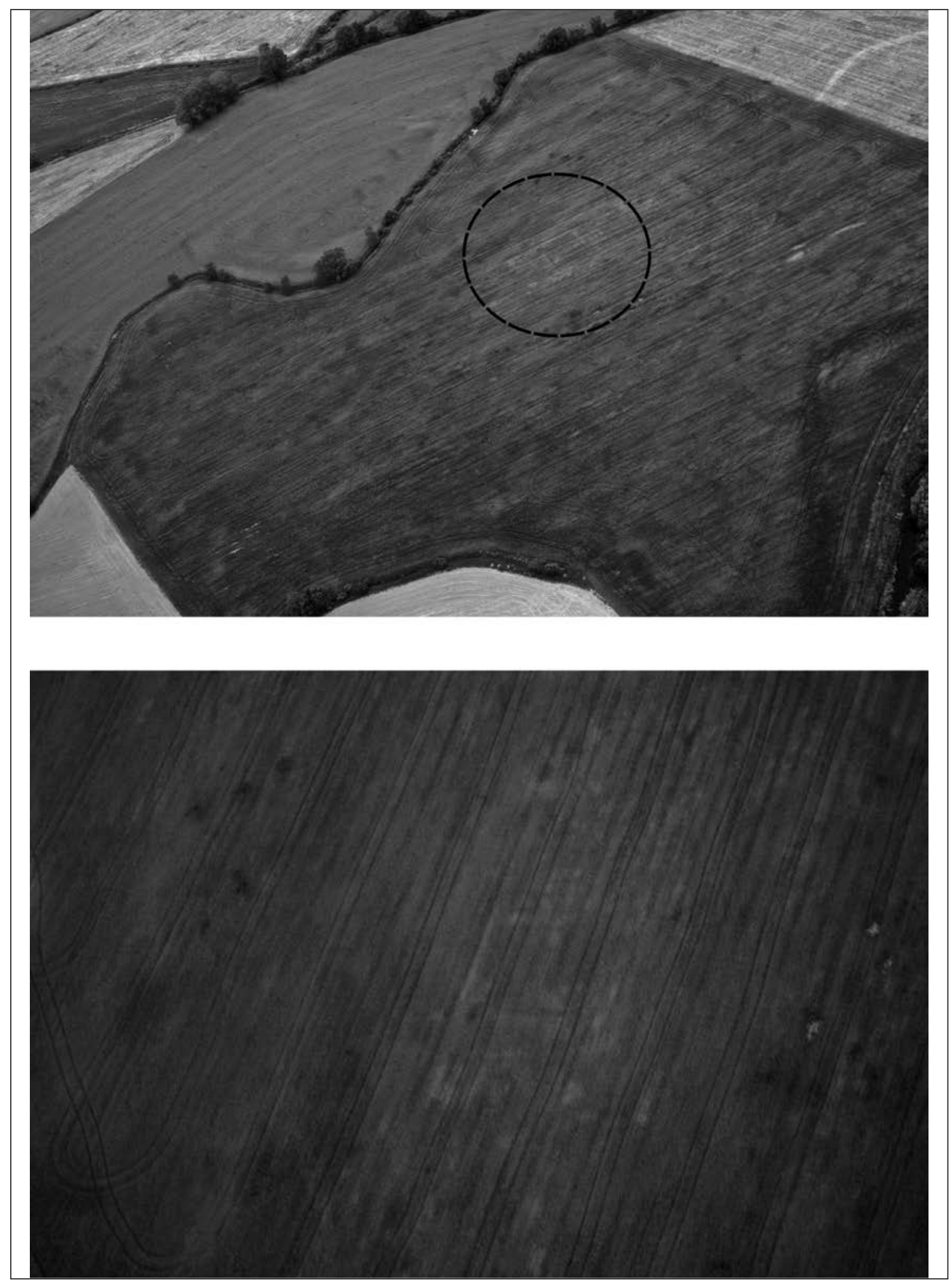

Figura 4. Fotografías aéreas oblicuas de Tisosa. Vuelo del 10 de junio de 2012 (J. García Sánchez). 


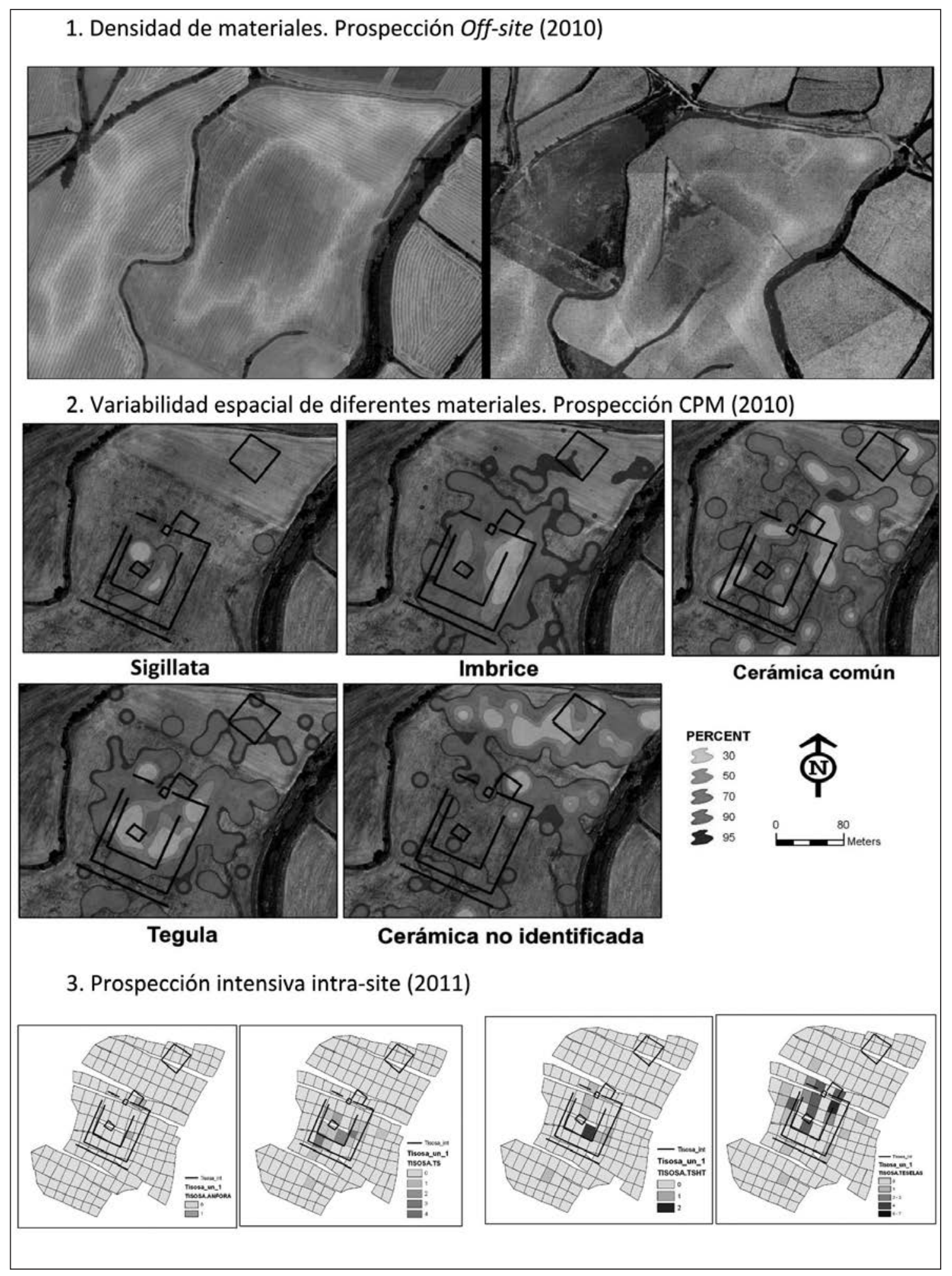

Figura 5. Metodología de los diferentes métodos de prospección o de la CPM (J. García Sánchez. 5.2 según García Sánchez 2013: 20). 
analizada por su incidencia en las ciencias sociales (Fotheringham y Wong 1991; Gregory 2003). Nuestra opinión, a partir de los resultados de varias experiencias de aplicación (García Sánchez 2013), es que esta metodología puede convertirse en un sistema de registro básico útil para una definición precisa de la extensión de yacimientos o para una posible identificación de tipologías de asentamientos o funcionalidades específicas. No obstante, un grado de detalle en la evolución cronológica o en la variabilidad funcional del espacio doméstico solo puede alcanzarse a partir de muestreos intensivos o de la elaboración de colecciones amplias de materiales, que dan cuenta de la diversidad del registro material y de los procesos de formación, tanto culturales como naturales, en estructuras domésticas, en las fases de uso, abandono y después del abandono (LaMotta y Schiffer 1999: 29). A este respecto, conviene recordar que algunos trabajos que integran tanto fotografía aérea como prospección regional y muestreos intrasite se han consolidado ya en el ámbito mediterráneo (Vermeulen et alii 2013: 270-278).

Nuestra primera valoración de los trabajos indicaba que los registros efectuados se centraban principalmente en el material constructivo, información esta que no era suficiente para una clasificación cronológica y funcional del yacimiento, aunque a juzgar por algunos materiales anfóricos su origen podría estar en momentos previos al cambio de Era. Por ello, en septiembre de 2011 volvimos a plantear una nueva prospección, orientada esta vez a la documentación intensiva del material de superficie, mediante el establecimiento de cuadrículas sobre dos parcelas de entre aquellas en las que habíamos encontrado restos materiales en las campañas anteriores. El objetivo era la detección de elementos diagnósticos, por lo que la metodología necesariamente debía aumentar la intensidad de supervisión de las unidades de muestreo definidas, con un tiempo de prospección estandarizado para permitir la comparación y la viabilidad de los resultados.

La principal característica de esta prospección intra-site es que sacrifica la alta resolución de las distribuciones de materiales obtenidas hasta la fecha, mediante la geo-localización de cada elemento, en beneficio de un mayor detalle en las colecciones de materiales (García Sánchez 2013), recopiladas en unidades homogéneas de 20 x 20 m durante un tiempo también homogéneo (diez minutos), que permite una supervisión intensiva. Esta metodología está orientada a la obtención de datos sobre la funcionalidad a grandes rasgos y la cronología del yacimiento, ya que los materiales recogidos en la prospección CPM únicamente pueden interpretarse en relación a la ex- tensión del yacimiento y a posibles zonas de diferente uso (Fig. 5).

Junto a la prospección, la fotografía aérea vertical y oblicua es la técnica que más información ha aportado sobre el yacimiento hasta estos momentos. La ortofoto del llamado vuelo americano de 1956 presenta una gran mancha oscura en el paraje de Tisosa, que coincide exactamente con la densidad de material registrado en la primera prospección off-site. En esa fecha todavía el cauce del río cubría parte de las parcelas actuales y los límites parcelarios respetaban el camino de Carremelgar. Estas imágenes, junto a las posteriores del PNOA, sobre todo a los fotogramas infrarrojos (PNOA-NIR), han permitido interpretar la planta del sitio de una forma un tanto somera, pero que admite ser contrastada con los datos espaciales recopilados en los primeros trabajos de prospección off-site. Esta primera interpretación muestra la imagen de una estructura de grandes dimensiones, quizá excesivas para una vivienda, aproximadamente 11326 $\mathrm{m}^{2}$. En la fotografía NIR también se puede apreciar una pequeña estructura de $280 \mathrm{~m}^{2}$ con un pequeño ábside en uno de sus lados que coincide parcialmente con otra visible en la fotografía realizada en el vuelo del 10 de junio de 2012. En este pudimos observar una nueva estructura cuadrangular (de unos 31 x 23 $\mathrm{m}$ y un área de $713 \mathrm{~m}^{2}$ ) (Fig. 6) gracias al cambio de coloración en el cultivo quizá debido a la conservación del suelo de la posible construcción. A este respecto, es interesante señalar que en la prospección de 2011 se hallaron cincuenta y cinco teselas y un pequeño fragmento de mosaico con bandas de tres colores.

Esta estructura se podría interpretar como un edificio con un cuerpo principal, una entrada y una pequeña zona adosada en la cabecera del mismo (Fig. 6), pudiéndose apreciar también el antiguo lecho del río Brullés y lo que parece ser una posible vía de acceso desde el antiguo camino de Carremelgar y en la parcela anexa otra pequeña estructura cuadrangular aislada.

Este tipo de imágenes oblicuas, correctamente orto-rectificadas, han sido comparadas con otros documentos cartográficos y fotográficos como los anteriormente mencionados y también, con las capas vectoriales de información temática generada en todas las prospecciones llevadas a cabo hasta la fecha. En función de estos elementos y de los materiales recuperados es posible ofrecer una valoración e interpretación del yacimiento, aunque las características intrínsecas de las metodologías no-destructivas utilizadas nos impiden, por ahora, alcanzar un nivel de detalle mayor en la organización interna del espacio de este significativo lugar que perdura desde el alto imperio a época tardía. 


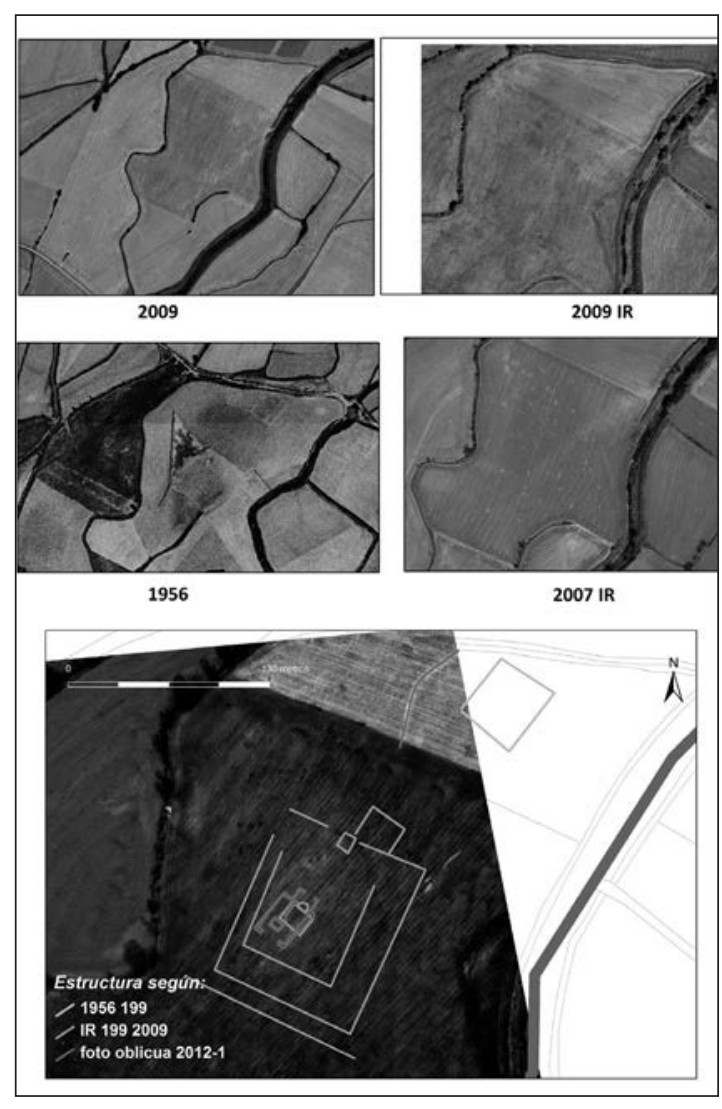

Figura 6. Fotointerpretación de Tisosa (J. García Sánchez).

\section{LOS MATERIALES DIAGNÓSTICOS Y SIGNI- FICATIVOS}

Las diferentes prospecciones en el paraje han permitido documentar una serie de materiales diagnósticos (fragmentos de ánforas de cronología tardorrepublicana-augústea e imperial, de una pieza de terracota decorada a molde, de varios vasos cerámicos de cocina tarraconense, de fragmentos de terra sigillata hispánica (TSH) y terra sigillata hispánica tardía (TSHT), y de numerosas teselas de mosaico e incluso algún fragmento de vidrio de ventana), que permiten proponer una hipótesis sobre la funcionalidad del yacimiento en una zona suburbana de Segisamo, aunque su cronología plantee algunos interrogantes, como veremos al final de este trabajo. Obviaremos en este apartado el material constructivo, aunque es el elemento más numeroso, ya que durante los trabajos de documentación solo ha sido abordado desde un punto de vista cuantitativo.

No obstante, sí que conviene destacar que se han contabilizado 2010 fragmentos de material constructivo, de los cuales 195 pertenecen a partes bien identificadas de tégulas y el resto, 1.815 fragmentos, corresponde a ímbrices, junto con otros materiales constructivos indeterminados, pero diferenciados de la característica forma de la teja plana.

El material mueble recogido se compone de una muestra de 393 elementos, quizá más escasa de lo esperado, a tenor del número total de artefactos cuantificados. En la figura 7 enumeramos los elementos detectados para cada clase. La documentación de teselas, por prospectores noveles, nos confirma la validez del método de registro propuesto, recordando que el objetivo es una documentación intensiva del material del yacimiento más allá de los omnipresentes datos del material constructivo. Sin embargo, la escasa presencia de vajilla de mesa $\mathrm{u}$ otros objetos de uso cotidiano, como lucernas o monedas, impide completar los datos cronológicos que ofrece el material cerámico.

La TSH y TSHT aparece en muy escaso número, únicamente veintinueve fragmentos de las primeras y nueve de las segundas, pertenecientes a formas no identificadas que se distribuyen en la zona central del yacimiento. Estos son los principales testimonios cronológicos del asentamiento. Tisosa pudo integrarse en el ámbito periurbano de Segisamo (Pradales y Gómez Santa Cruz 2003: 63), como centro explotador de la vega del río o quizá, también podría ser muy sugerente, aunque los datos no sean concluyentes, como puesto de control de los ramales que accedían a la ciudad desde la vía Asturica-Burdigala o desde la que la comunicaba con Pisoraca. La presencia de estos materiales, sin embargo, no tendrá un sentido completo hasta que se desarrolle una investigación estratigráfica en la zona en la que la fotografía aérea oblicua muestra posibles estructuras y la prospección superficial documenta la máxima densidad de elementos materiales recopilados.

Respecto a las ánforas disponemos de cinco fragmentos, tres fueron localizados durante la prospección denominada CPM (García Sánchez 2013) y dos durante la prospección intra-site de 2011 (Fig. 7). De las cuales cuatro son asas (números de inventario: $10.21 .052,10.21 .124,11.23 .501$ y 11.23 .502$)$ y una un pivote (número de inventario: 10.21.123). El fragmento 10.21.052 es una forma Haltern 70, que procede de los talleres del Valle del Guadalquivir y se encuentra vinculada al ámbito militar desde momentos tempranos augústeos (Berni 2011: 87), consolidándose con Tiberio en el abastecimiento de las guarniciones del limes germano. Se trata de un envase destinado preferentemente al transporte de vino cocido, defrutum, bien como producto en sí mismo, bien como conservador de olivas (Beltrán 1997: 77; Carreras y Berni 2003: 640). Aunque está muy difundido por la 


\begin{tabular}{|lrrc|}
\hline & $\mathbf{N}^{\mathbf{0}}$ & Peso (gr.) & $\begin{array}{c}\text { Media por unidad de prospección } \\
\text { (N/169) }\end{array}$ \\
\hline Material Inventariado & & & \\
\hline Ánfora & 2 & 254.5 & 0.012 \\
Cerámica de Cocina & 4 & 69.3 & 0.024 \\
Cerámica Común & 56 & 805.8 & 0.331 \\
Común moderno & 68 & 510.8 & 0.402 \\
Fragmentos indeterminados & 162 & 1575.6 & 0.959 \\
Sigillata Hispánica & 29 & 105.5 & 0.172 \\
Sigillata Tardía & 9 & 51.1 & 0.053 \\
Tesela & 55 & 211.7 & 0.325 \\
Otros materiales & & & 0.036 \\
\hline Loza Moderna & 6 & & 0.550 \\
Vidriado & 93 & & 1.154 \\
Material Constructivo & & & 10.740 \\
\hline Tegula & 195 & & \\
Imbrice & 1815 & & \\
\hline
\end{tabular}

Figura 7. Cuantificación de los materiales hallados en la prospección de 2011 (J. García Sánchez).

franja costera del levante hispano, mientras que en el valle del Ebro solo lo está en la Colonia Celsa, nos interesa destacar su profusión en el norte peninsular, principalmente en Uxama, Petavonium, Legio, Asturica Augusta (donde es una de las formas mejor representadas), Campa Torres, en la mayoría de los enclaves de la costa galaica, Bracara Augusta y Porto (Beltrán 1997: 77; Carreras y Berni 2003: 655; Carreras y Morais 2004). Su localización en Sasamón es, por tanto, coherente con las rutas de distribución del norte peninsular (Fig. 8.1).

El fragmento 11.23.501 se trata del arranque inferior de un asa que podemos identificar con una forma Dressel $1 \mathrm{C}$, de origen itálico, si bien la ausencia de morfología concreta impide clasificarlo dentro de las variantes que se establecen en esta forma, en las que la modalidad de labio, unida a las asas flexionadas, quizá como en nuestro ejemplar, permiten determinadas aproximaciones tipológicas (Fig. 8.2), mientras que el fragmento 10.21.123 es un pivote de Dressel 1B de fabricación campana, por la presencia de material volcánico en la pasta. Ambas formas, usadas como contenedores de vino, son habituales desde finales del siglo II y el primer cuarto del I a.C., como atestiguan los hallazgos en algunos pecios (Parker 1992: 133) (Fig. 8.3).

El fragmento 10.21.124 es parte de un asa de tipo "rodio". Su pasta de color beige muy depurada, sin desgrasante visible, se podría corresponder con el tipo
II de Peacock (1986: 102), aunque algunos autores se muestran cautos con la atribución de la zona de producción a partir de algunos resultados analíticos (Beltrán 1997: 68). Se empleó fundamentalmente

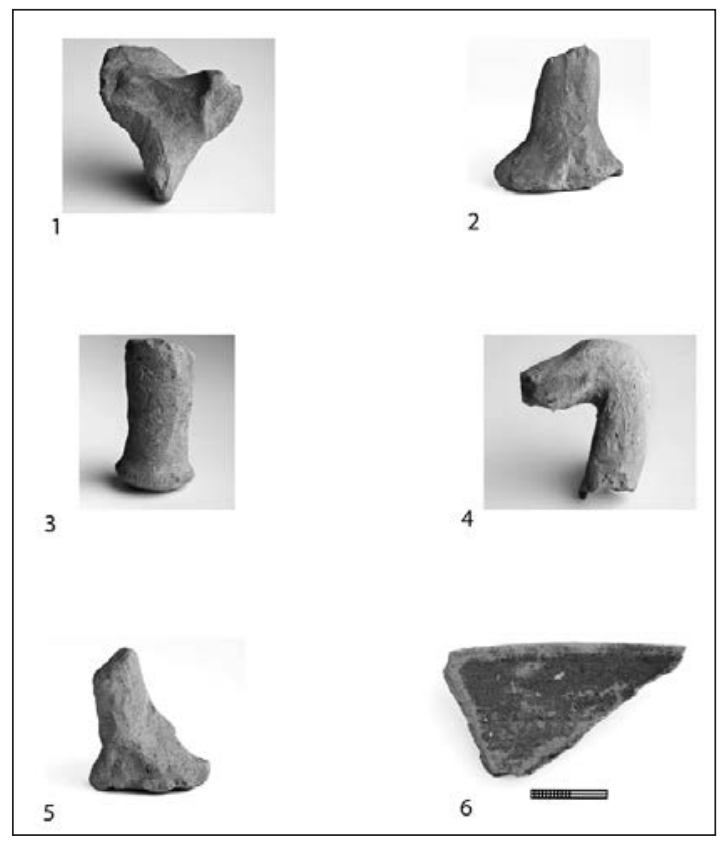

Figura 8. Materiales cerámicos: ánforas y cerámica de imitación de engobe rojo pompeyano (Fotografías: J. Romeo). 
para transportar vino del Egeo y en menor medida higos (Carreras y Berni 2003: 647). Se distribuye mayoritariamente por el Egeo, la Cirenaica, Italia, Francia, Germania, Panonia, Suiza y Bretaña (Peacock 1977). En la Península Ibérica está documentada en la Colonia Celsa (Beltrán 1997: 67-68) y en Asturica Augusta, donde es una de las formas más abundante (Carreras y Berni 2003: 646-647) (Fig. 8.4).

El último fragmento, 11.23.502, corresponde al engaste superior de un asa de tendencia horizontal muy rodado. La ausencia de morfología concreta impide clasificar el fragmento de acuerdo a un tipo ajustado, que quizá podría tratarse de Oberaden 74/Dr. 28. Esta forma surge en la etapa augústea, confirmándose su cronología temprana, antes del 30 a.C. aproximadamente, en Baetulo (Comas 1985: 21), perdurando en época claudia. Estos tipos tienen una amplia dispersión en la Tarraconense y el Occidente romano (Miró y Canals 1988: 219). El contenido de estas ánforas fue verosímilmente el del vino, como evidencian los recubrimientos de pez de Port Vendres II (Colls et alii 1977: 45) y sobre todo el parentesco de estas formas con las semejantes de origen gálico, que envasaron entre otros el vino de Marsella (Brentchalof 1980: 98) (Fig. 8.5).

Entre los fragmentos de cerámica común de cocina, destacamos un borde de patina con engobe rojo interno (número de inventario 11.23.504) que podría corresponderse con una imitación de engobe rojo pompeyano de fabricación tarraconense (Lapuente et alii 1996). La presencia de las cerámicas de engobe interno rojo pompeyano ha sido considerada como un indicador del proceso de romanización del sector septentrional de la Península Ibérica (Girón y Costa 2009: 497). Estas imitaciones se documentan desde mediados del siglo I d.C. y a lo largo de la siguiente centuria (Lapuente et alii 1996: 89), sugiriéndonos, asimismo, la presencia de individuos de gustos itálicos, por cuanto el principal uso de este vaso cerámico fue, según Pucci (1975), el de cocinar la patina, un plato característico de la dieta romana compuesto por carne, pescado y verduras mezclados con salsas y huevos (Girón y Costa 2009: 498) (Fig. 8.6).

La pieza 10.21.100 es más problemática y su funcionalidad está todavía por definir con seguridad. Se trata de un fragmento, posiblemente un friso o una sima (cuyas medidas son: $8,5 \mathrm{~cm}$ de largo, $9 \mathrm{~cm}$ de ancho, ambos lados están incompletos, y $5,5 \mathrm{~cm}$ de altura), correspondiente a una esquina de un elemento fabricado en terracota, decorado a molde con motivos sencillos en las partes conservadas de dos de sus lados: en uno presenta un roleo de guirnaldas y en el otro, una crátera o vaso. La parte superior tiene forma de cavidad rectangular o cuadrada biselada al interior. La fractura de su parte inferior nos indica su pertenencia a un coronamiento o cuerpo superior de un elemento de forma prismática, rectangular o cuadrada (Fig. 9). Sobre él podemos plantear diversas hipótesis funcionales debido a su tamaño, forma y decoración. Esta a partir de los roleos y quizá de la crátera nos podría indicar su pertenencia a un edificio religioso, un templo, o funerario, un edículo o un altar, si su tamaño fuese mayor; a este respecto pueden verse algunos ejemplos de Pompeya (D'Ambrosio y Borriello 1990; VV. AA. 1996), del Museo Nazionale Romano (Pensabene 1999: 44 y 46 especialmente para algunas simas) o de los templos lunenses (Forte 1991: n 159, 160, 163 y 164). De aceptar esta similitud estaríamos ante la decoración de un edificio de pequeño tamaño, pero de características domésticas, dado el contexto en el que ha sido hallado el fragmento.

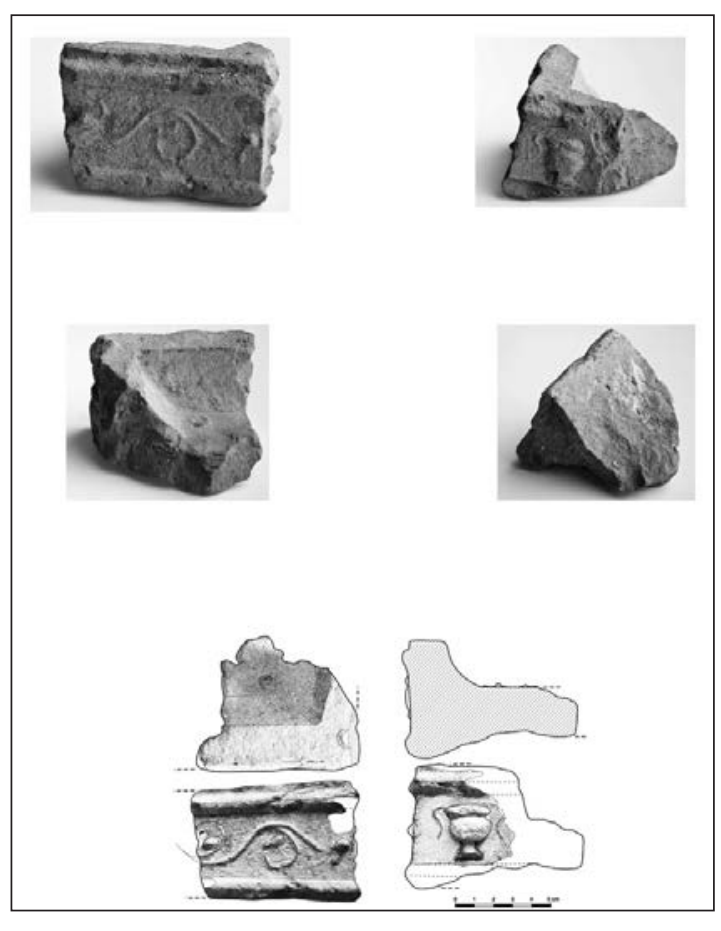

Figura 9. Elemento de terracota perteneciente posiblemente a un edificio religioso o funerario de pequeño tamaño (Fotografías: J. Romeo; dibujos: Maricruz Sopeña).

En este sentido, podemos recordar que Ramos (1996: 201-202) ya planteaba en su publicación de las terracotas arquitectónicas de la Tarraconense una hipótesis similar al analizar ocho antefijas de tamaño muy reducido, entre 5,5 y $9,5 \mathrm{~cm}$ de largo, 6,6 y 12 $\mathrm{cm}$ de ancho y 2,7 y $5,2 \mathrm{~cm}$ de grosor, que por sus proporciones consideraba poco apropiadas para ser usadas en los tejados de un edificio; de ahí que con- 
cluyese que solo pudieron formar parte del tejado de un pequeño templo ubicado en el interior de la casa, que tendría una función de altar, haciendo visible de esta forma la decoración arquitectónica. De las ocho antefijas, solo a cuatro les pudo atribuir una cronología basada en análisis estilístico y no en contexto estratigráfico: una de Clunia, la fecha en época tardorrepublicana (Ramos 1996: 509) y dos de Complutum y una de la Villa del Val, en Alcalá de Henares, en la segunda mitad del siglo I d.C. (Ramos 1996: 437 y 454). Nuestro fragmento encajaría perfectamente en esta hipótesis, aunque esta investigadora no presente ningún ejemplo que la refrende. Nosotros tampoco hemos hallado paralelos, aunque algunos de los publicados entre los lararia de Pompeya podrían ir en esta línea (Boyce 1937: 41, nº 123 y 43, no 132), en relación quizá también con esas figurillas de pequeño tamaño, como las halladas en la villa del Paturro en Portman-Cartagena, que tenían una finalidad cultual, votiva o religiosa en el ámbito familiar (Fernández Díaz 1997: 151-152).

No obstante, y aunque esta nos parece la opción más factible, no descartamos en el estado actual de nuestra investigación, que pudiésemos estar ante una de las denominadas "cajitas celtibéricas" de época romana altoimperial, dada la forma que se deduce de la pieza, abierta en su parte superior, y el contexto regional del hallazgo, la Meseta Norte. Si bien bajo esa denominación se incluye un grupo muy heterogéneo de piezas rectangulares de cerámica, todas con cuatro patas, cuya apariencia externa puede ser lisa o decorada, y en este caso se distingue una gran variedad de técnicas, una imprecisa, y amplia, cronología y una finalidad no bien definida (Pérez González 1983: 13-18). Sin embargo, una de estas cajitas, procedente de Villabermudo (Palencia) y hallada en las proximidades de una excavación de urgencia, fuera de contexto arqueológico, presenta una decoración a base de un friso continuo de roleos de guirnaldas. Los investigadores consideran que esa decoración es del gusto romano, ya que está influida por los motivos de la sigillata, aunque su tamaño sea mayor que el del resto de las “cajitas" (Pérez González e Illarregui 1990: 300-301).

Ahora bien, el lugar de este hallazgo es muy interesante, puesto que podría tener algunas similitudes con el nuestro. Esta "cajita" fue encontrada en el paraje de Praderahonda, donde tradicionalmente se ha venido ubicando una villa romana, muy cerca, por otra parte, de Pisoraca. Pero ambas piezas difieren en su motivo decorativo, aun cuando puedan tener alguna semejanza, ya que la nuestra no tiene un motivo continuo que recorra todo su perímetro. Además, no presenta similitud alguna con las publicadas en las zonas próximas, ni por Abásolo y García (1993: 137, fig. 70) en su monografía sobre Sasamón, donde documentan dos en Tarreros de Villasidro, ni con otras publicadas por Pérez González (1983) en la provincia de Palencia, ni con las más recientes de la zona cántabra (Fernández Vega et alii 2010). Todo ello, nos hace ser cautos en cuanto a esta comparación, ya que si por el lugar de hallazgo podría tener una significativa similitud (villa próxima a campamento/ciudad romana), la decoración, por técnica y por motivos, no parece ser la propia de este conjunto de elementos y la de Villabermudo necesitaría un análisis en profundidad, dados los escasos datos proporcionados por sus autores y las discrepancias que plantea con los elementos característicos de un grupo mal definido por otra parte.

Una tercera opción, que barajamos inicialmente, la de que se tratase de un árula, debido a su decoración y a la forma de la parte superior que podría recordar a un focus para ofrendas, aunque no haya rastro de ellas, la hemos descartado, ya que la bibliografía al respecto no ofrece dudas. Montón (1990) estableció una clasificación de este tipo de elementos en su tesis doctoral a partir del estudio de las de los conventos caesaragustano y tarraconense, publicando en detalle, posteriormente, las de Tarraco (Montón 1996). Entre los tipos que describe, las piezas de terracota son una minoría, dos de los ochenta y tres ejemplares estudiados, no presentando parecido morfológico alguno con el nuestro. A conclusiones similares llegamos tras el análisis de las árulas de terracota de Pompeya (Elia 1962), de las del Sur de Italia y Sicilia (Van Buren 1918) o de las depositadas en el Anticuario de Roma (Ricciotti 1978), ya que no presentan una decoración similar y tampoco una cronología. Es decir, que ni la materia prima, ya que se trata de un elemento fabricado mayoritariamente en piedra, ni la morfología y decoración permiten su asociación.

A la presencia de este material se puede añadir el hallazgo de teselas, en especial, un fragmento de opus tessellatum en el que se combinan teselas de colores blanco, negro y rojo, formando cuatro líneas con tendencia circular. Estos escasos restos musivos son poco representativos cronológicamente, si bien hay que tener en cuenta que los mosaicos publicados en la Meseta Norte no son anteriores al siglo II, encontrándose mayoritariamente relacionados con las villae y sus fases tardías de ocupación (López Monteagudo y Mañanes 1993; Regueras y Pérez Olmedo 1997; Neira y Mañanes 1998; Regueras 2002), y los referidos a la zona se fechan a partir de finales de dicho siglo, como el hallado en Sasamón, o en el siglo IV, como el de Barruelo de Villadiego (López Monteagudo 1998: 20 y 36 especialmente). En todo 
caso, nos indica la existencia de espacios de carácter privado pertenecientes, posiblemente, a la vivienda del propietario, como se ha documentado en la mayoría de los ejemplos recogidos en la bibliografía citada.

\section{CONSIDERACIONES FINALES}

Segisamo es un ejemplo de fundación ex novo en las proximidades de un hábitat anterior, procedimiento este utilizado por los romanos en otros casos no solo en la Meseta norte, como en Pisoraca, Clunia o Deobrigula por ejemplo (López Noriega 1997; 1998), sino también en otras zonas de Hispania, como en su momento estudió Pina Polo (1993), significando el nuevo emplazamiento un cambio de ubicación dentro del mismo territorio, no afectando a su condición jurídica. De esta forma quizá podemos entender las acepciones de Segisama y Segisamo, cuya reducción ha originado un debate ya comentado en la introducción de este trabajo.

Pero además Segisamo surge a partir de un establecimiento militar previo, siendo un testigo más de la influencia que el ejército romano tuvo en ese proceso que se ha denominado genéricamente como romanización y en el importante papel que desempeñó en la organización del territorio y dentro de esta en el reparto de tierras unido a la fundación de ciudades, como es conocido y han destacado algunos autores (Marco et alii 2008: 175). A este respecto, es conveniente recordar que en el contexto de las guerras cántabras varias legiones se asentaron en la Meseta Norte para controlar los frentes astur y cántabro y en este último la legio IIII Macedonica se instaló en Herrera de Pisuerga hasta el 39-40 d.C., tras pasar por Segisamo, donde Augusto había ubicado su campamento, según Floro. Esto significó que el ejército romano y sus canabae fundaron también la ciudad de Pisoraca (López Noriega 1997: 218-219), aunque desde el punto de vista arqueológico haya sido imposible encontrar un correlato a los hechos narrados no solo por Floro, sino también por Orosio.

Arqueológicamente hay tres elementos de distinta naturaleza que mantienen esta vinculación: en primer lugar, algunos autores, como Abásolo (1975), plantearon la asociación de Sasamón con el campamento original y aunque no han aparecido restos de construcciones o materiales que lo avalen (Abásolo y García 1993), esta atribución viene siendo aceptada tradicionalmente; incluso algunos investigadores, como Morillo (1991: 161; 1993: 391), han planteado que quizá estemos ante algún asentamiento de menor entidad cercano a la ciudad turmoga, tal vez la propia Herrera de Pisuerga.
En segundo lugar, los termini pratorum de la legio IIII Macedonica que delimitaban sus zonas de prados de las poblaciones vecinas de Iuliobriga y de Segisamo, también citados con anterioridad, y, en tercer lugar, la inscripción votiva de Aelius Maritimus, b(ene)f(iciarius) co(n)s(ularis), a entre otros el genio stationis Segisamonensium, que mencionaba una exedra cum basi, cuya cronología Gómez Pantoja (1992) sitúa en el siglo II o en el primer cuarto del III, sosteniendo que algunos contingentes o individuos destacados del ejército se mantuvieron en Segisamo hasta ese momento, si bien Solana (1976) la fecha en época claudia. De cualquier forma, como señalan algunos autores (Marco et alii 2008: 175-176), el monumento indica la importancia del establecimiento, siendo la única "estación" militar conocida en Hispania a través de la epigrafía.

En este sentido, creemos que el yacimiento y los materiales de Tisosa podrían aportar nueva información sobre: los momentos iniciales y, quizá, la presencia del ejército, la relación del yacimiento con la posible fundación de Segisamo y la organización del paisaje, que posteriormente quedará marcada por el ya mencionado hito de Villasidro.

A la vista de los materiales hallados y de su distribución podemos hacer una interpretación general de este conjunto, con las limitaciones que lleva el hecho de que sean procedentes de prospección y del escaso número hallado para algunos tipos, que indicaría una cronología del sitio desde el siglo I d.C. hasta época tardía, sin que podamos asegurar que la ocupación sea continuada ni que se hubiese iniciado con anterioridad, como podrían señalar algunos fragmentos de ánforas (Fig. 10).

A este respecto y con las cautelas citadas, la presencia especialmente de la Haltern 70, dada su aparición en contextos vinculados con el ejército, como ya hemos comentado, y, posiblemente, de la Dressel 1B y 1C podrían sugerir una relación con los momentos de control de la zona septentrional de la submeseta norte por parte de las legiones romanas (IIII Macedonica, VI Victrix, X Gemina) involucradas en las guerras contra cántabros y astures en el norte peninsular (Morillo et alii 2008; Morillo 2011). Si bien, la Haltern 70 podría no ser contemporánea de estos momentos, dado su arco cronológico (Fig. 10), y asociarse a contingentes militares existentes en la zona; en este sentido, no podemos olvidar la mencionada inscripción votiva de Aelius Maritimus, que alude a una estación militar y, por tanto, a la presencia de algún destacamento en fechas alejadas del conflicto bélico.

En este contexto es en el que deberíamos considerar la presencia de individuos de origen o costumbres 


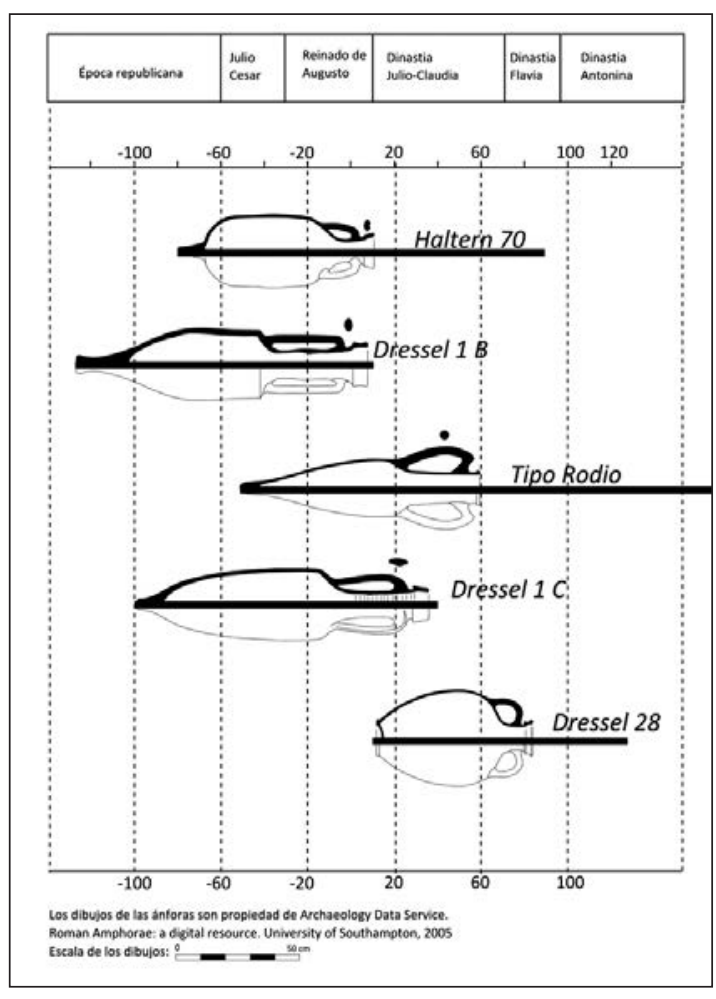

Figura 10. Tabla cronológica de las ánforas halladas (J. García Sánchez).

itálicas que provocaron la importación de productos de indudable gusto greco-latino, como algunos de los comentados: el vino distribuido en las ánforas, la cerámica de imitación de engobe rojo pompeyano de fabricación tarraconense o incluso el fragmento de terracota decorado, que pudo pertenecer a un edículo doméstico en forma de pequeño templete, aunque otras posibilidades también son factibles, como hemos apuntado.

Aceptar estas fechas tan tempranas y la vinculación del yacimiento con los momentos fundacionales y el ejército es sugerente, pero reiteramos que se basa en una escasa muestra e incluso en aquellos materiales cuantitativamente menos numerosos, aunque sean de los más representativos, por lo que creemos debe plantearse como un hipótesis, dejando abiertas otras posibilidades.

Menos dudas surgen sobre la existencia del yacimiento en el siglo I d.C. como indican algunos materiales, al margen de los constructivos, como tejas o ladrillos: las ánforas, excepto la Dressel 1B y 1C, son de frecuente aparición a los largo de esta centuria, el fragmento de terracota citado, que de aceptar las fechas dadas procedentes de análisis estilísticos para antefijas de tamaño similar, que encajarían bien con nuestra pieza, se fecharía entre momentos tardorrepublicanos y la segunda mitad del siglo I d.C., y la presencia de los fragmentos de TSH. Y tampoco parece dudosa su perduración en época tardía como señalarían los fragmentos de TSHT y posiblemente las teselas y el fragmento de mosaico.

El establecimiento tuvo que integrarse en el panorama periurbano de la ciudad, viéndose beneficiado por la promoción de Segisamo a municipio en época flavia, gracias al ius Latium minus (Orejas 2002; Pradales y Gómez Santa Cruz 2003: 63), dentro de una organización del espacio agrario, que, como uno de nosotros ya ha planteado (García Sánchez 2009), adquirió desde el siglo i d.C. características plenamente romanas, tanto en el entorno urbano como en la propia gestión de los recursos económicos y en las estrategias conducentes a la creación de un patrón de asentamiento adecuado a las nuevas necesidades. Así, la explotación de las fértiles vegas del Odra, Brullés, Pisuerga o Duero requirieron de un nuevo modo de actuar sobre el paisaje (dwelleing landscape) y los nuevos núcleos urbanos, junto a las villas altoimperiales dependientes de ellos, serán los testigos arqueológicos de tal proceso (Palomino et alii 2012: 297-299). A este respecto, es significativo que algunos autores (Morillo 2000: 614) adscriban la cronología de los hitos terminales de la legio IIII Macedonica, entre los que se encuentra el ejemplar de Villasidro a época tardoaugústea o tiberiana (Cortés 2009: 98), ya en el siglo i d.C., lejos del contexto de las guerras contra cántabros y astures, pudiendo interpretarse, en definitiva, como un testimonio del nuevo sistema de organización del territorio.

El estudio de la ocupación romana de este paisaje (García Sánchez 2009) se ha llevado a cabo a partir de los registros de Cartas e Inventarios elaborados a partir de los años setenta del pasado siglo. El conocimiento de los yacimientos que aparecen en estos inventarios debe considerarse como parcial y los sitios que han sido estudiados sistemáticamente son escasos, con la salvedad de los grandes centros urbanos como Amaya, Deobrigula, Segisamo y Dessobriga, por citar algunos de los más cercanos. Quizá no ha sido posible emprender grandes esfuerzos de excavación o prospección sistemática por la amplia extensión del fenómeno rural que se desarrolla en el mundo romano, materializada en la construcción de un gran número de asentamientos rurales, considerados en la tradición historiográfica como villas, y especialmente desde el siglo II (Pradales y Gómez Santa Cruz 2003: 62).

En el propio entorno de Segisamo tenemos constancia, a través de las prospecciones y de la carta arqueológica (Abásolo 1978), de otros yacimientos cuyo origen se puede retrotraer a los siglos I y II 
d.C. y que perduran varios siglos. El más cercano en espacio es el de El Polear, identificado en nuestra prospección del año 2010, que a partir algunos de los materiales hallados, es significativo un borde de Isings 50, estaría ya en funcionamiento en época flavia. Este yacimiento se ubica junto a la vía secundaria Pisoraca-Segisamo en un paraje llano, cercano a cauces menores de agua, lo que nos lleva a pensar en una pequeña granja rural, que contribuiría a sistematizar una ocupación del espacio, que poco tiene que ver ya con el modo prerromano de subsistencia, caracterizado por grandes núcleos fortificados y ninguna ocupación secundaria de poblamiento, aunque esta visión necesite forzosamente ser contrastada con la realidad arqueológica, ya que no es coincidente con los datos que tenemos de otras partes del mundo protohistórico ibérico, donde sí que existe ese tipo de poblamiento rural o campesino.

En este sentido Tisosa representa solo un apunte del proceso de ocupación del espacio según una estrategia claramente romana, cuyos actores parecen apostar en un primer lugar por la ocupación de los ámbitos más próximos a los núcleos urbanos y posteriormente de los amplios espacios de campiña. El diseño de una demarcación del ager de los Segisamonenses, que atestigua el epígrafe de Villasidro, es la principal evidencia de una ocupación consciente y planificada del norte de la Meseta.

Tisosa, como yacimiento suburbano, es un elemento novedoso en la investigación del pasado romano de Sasamón y marca una pauta que se desarrollará a lo largo de los primeros siglos de la era, desde un posible origen vinculado al ejército y ligado a la conquista hasta una completa desvinculación de los centros urbanos, pasando por quizá un tutelaje por parte de Segisamo, cuyo sentido podría conocerse mediante otro tipo de investigaciones arqueológicas. En una evolución del ámbito urbano a la creación del sistema vilicario similar a la de otras zonas del valle del Duero, en los entornos urbanos de Rauda y Clunia (Palomino et alii 2012: 297-300).

El régimen vilicario del Bajo Imperio en el valle del Duero es más visible, aunque los lugares bien excavados sean escasos; entre estos encontramos los grandes yacimientos de La Olmeda, Quintanilla de la Cueza (Palencia), Santa Cruz de Valdearados (Burgos), Almenara de Adaja (Valladolid), Navatejera (León), Los Quintanares (Soria) u otros conocidos por excavaciones puntuales, debido a sus pavimentos o por su descubrimiento a través de la fotografía aérea (García Merino 2008: 421-422), pero el enfoque sigue centrándose en los aspectos urbanos del fundus, complementados con algunos trabajos sobre los aspectos productivos o la organización del territorio (Orejas y
Ruiz del Árbol 2008), que, sin duda, deben formar parte de un estudio de la colonización del paisaje de forma diacrónica. En este sentido desde 2012 venimos promoviendo un proyecto de prospección sistemática y fotografía aérea para desentrañar los mecanismos de ocupación y explotación del valle del Odra, desde su nacimiento en Fuenteodra hasta su unión con el cauce del Brullés en las inmediaciones de Villasandino, una zona que debió sin duda estar mediatizada por la presencia de Segisamo y las vías romanas, la vía 34 del Itinerario de Antonino y la vía secundaria hacia Pisoraca, y en el que Tisosa representa el primer establecimiento suburbano localizado en la región.

\section{BIBLIOGRAFÍA}

Abásolo, J. A. 1975: "Notas sobre el campamento romano de Sasamón (Burgos)", Pyrenae 11, 127-137.

Abásolo, J. A. 1978: Carta arqueológica de la provincia de Burgos. Partidos judiciales de Castrojeriz. y Villadiego, Burgos.

Abásolo, J. A. y García, R. 1993: Excavaciones en Sasamón (Burgos), Excavaciones Arqueológicas en España 164, Madrid.

Abasolo, J. A. 1998: "La ciudad de Segisamo", A. Rodríguez Colmenero (ed.), Los orígenes de la ciudad en el Noroeste hispánico. Actas del Congreso Internacional, Lugo, 585-598.

Anschuetz, K. F., Wilshusen, R. H. y Scheick, C. L. 2001: "An Archaeology of Landscapes: Perspectives and Directions", Journal of Archaeological Research 9 (2), 152-197.

Beltrán, M. 1997:“Contenedores de consumo y transporte”, M. Beltrán, C. Aguarod, M. A. Hernández Prieto, J. A. Mínguez y J. Á. Paz, Colonia Victrix Iulia Lepida-Celsa (Velilla de Ebro, Zaragoza). III, 1: El instrumentum domesticum de la "Casa de los Delfines", Zaragoza, 65-108.

Berni, P. 2011: “Tipología de la Haltern 70 bética”, C. Carreras, R. Morais y E. González Fernández (eds.), Ánforas romanas de Lugo, Lugo, 80-107.

Bintliff, J. 2000: "The concepts of 'site' and 'offsite' archaeology in surface artefact survey" G. Barker y D. Mattingly (eds.), Non-Destructive Techniques applied to Landscape Archaeology. The Archaeology of Mediterranean Landscapes, Oxford, 200-215.

Bintliff, J. y Snodgrass, A. 1988: “Off-Site Pottery Distributions: A Regional and Interregional Perspective", Current Anthropology 29 (3), 506-513.

Boyce, G. K. 1937: "Corpus of the Lararia of Pompeii", Memoirs of the American Academy in Rome 14, 5-112. 
Brentchalof, D. 1980 : “L'atelier de Pauvadau. Une officine de potiers flaviens à Frejus", Revue d'Archéologie Narbonnaise 13, 72-114.

Carreras, C. y Berni, P. 2003:“Ánforas”, M. T. Amaré (dir.), Astorga IV. Lucernas y ánforas, León, 633-673.

Carreras, C. y Morais, R. 2004: "Geografia del consum de les Haltern 70”, Culip VIII i les àmfores Haltern 70, Girona, 93-115.

Cisneros, M. y López Noriega, P. 2004: "El sistema defensivo del castro de La Ulaña (Humada, Burgos)", Archivo Español de Arqueología 77, 3-22.

Cisneros, M. y López Noriega, P. 2005: El castro de La Ulaña (Humada, Burgos). La documentación arqueológica. 1997-2001, Santander.

Cisneros, M. 2008: "La Ulaña (prov. Burgos). Ein Oppidum der Jüngeren Eisenzeit im Norden der Iberischen Halbinsel", Madrider Mitteilungen 49, 209-228.

Colls, D., Étienne, R., Lequément, R., Liou, B. y Mayet, F. 1977: L'epave Port Vendres II et le commerce de la Betique à l'epoque de Claude, Archeonautica 1, Paris.

Comas, M. 1985: Baetulo. Les anfores, Monografies Badalonines 8, Badalona.

Cortés, C. 2009: "El territorio militar en la epigrafía de la Hispania romana: los termini pratorum", Á. Morillo, N. Hanel y E. Martín (eds.), Limes XX. Estudios sobre la frontera romana / Roman Frontier Studies, Anejos de Gladius 9, Madrid, 91-101.

Crespo, S. y Alonso, A. 2000: Corpus de inscripciones romanas de la provincia de Burgos. Fuentes epigráficas para la historia social de Hispania romana, Valladolid.

D'Ambrosio, A. y Borriello, M. 1990: Le terracotte figurate di Pompei, Roma.

Didierjean, F. y Abásolo, J. A. 2007: “La vía Aquitana. Aportaciones de la fotografía aérea”, M. Navarro y J. J. Palao (eds.), Villes et territoires dans le bassin du Douro á l'époque romaine: actes de la table-ronde, Bordeaux, 395-427.

Elia, O. 1962: "Culti familiari e privati della Campania", Latomus LVIII, 2. Hommages à Albert Grenier, 559-566.

Fernández Díaz, A. 1997: "Terracotas de la villa romana de la huerta del Paturro en Portmán-Cartagena", XXIV Congreso Nacional de Arqueología, Cartagena, 151-160.

Fernández Vega, P. A., Bolado, R., Callejo, J. y Mantecón, L. 2012: "Un nuevo término augustal del ager Iuliobrigensium", Archivo Español de Arqueología 85, 267-271.

Fernández Vega, P. A., Bolado, R. Illaregui, E. y Peñil, J. 2010: "Hallazgo de dos 'cajitas celtibéricas' en Camesa-Rebolledo (Valdeolea, Cantabria)", Munibe 61, 221-234.

Foley, R. 1981: "Off-site archaeology: an alternative approach for the short-sited", G. Isaac y N. Hammond (eds.), Pattern of the Past. Studies in Honour of David Clarke, Cambridge, 13-35.

Forbes, H. 2013: "Off-Site Scatters and the Manuring Hypothesis in Greek Survey Archaeology: An Ethnographic Approach", Hesperia 82 (4), 551-594.

Forte, M. 1991: Le terracotte ornamentali dei templi lunensi, Firenze.

Fotheringham, A. S. y Wong, D. W. S. 1991: "The modifiable areal unit problem in multivariate statistical analysis", Environment and Planning 23 (7), 1025-1044.

Fuentes, J. L. 1989: El suelo y los fertilizantes, Madrid. García Merino, C. 1975: Población y poblamiento en Hispania romana. El Conventus Cluniensis, Valladolid.

García Merino, C. 2008: "Almenara de Adaja y las villas de la submeseta norte", C. Fernández Ochoa, V. García-Entero y F. Gil Sendino (eds.) Las villae tardorromanas en el Occidente del imperio: arquitectura y función. IV Coloquio Internacional de Arqueología en Gijón, Gijón, 411-434.

García Sánchez, J. 2009: "El poblamiento y la explotación del paisaje en la meseta norte entre la edad del hierro y época romana altoimperial. Una aproximación a través de la arqueología espacial", Zephyrus 59, 81-96.

García Sánchez, J. 2012: Arqueología y paisaje en el noroeste de Burgos: la transición de la Segunda Edad de Hierro a época romana a través del registro material, http://www.tdx.cat/handle/10803/80486 (2 de agosto de 2012).

García Sánchez, J. 2013: "Metodologías de prospección a escala regional y artefactual. La prospección del Ager Segisamonensis; comarca Odra-Pisuerga (Burgos)", Complutum 24 (1), 9-28.

García Sánchez, J. y Cisneros, M. 2013: “An off-site approach to Late Iron Age and Roman landscapes in the Northern Plateau, Spain", European Journal of Archaeology 16 (2), 289-313.

García y Bellido, A., Fernández de Avilés, A. y García Guinea, M. Á. 1970: Excavaciones y exploraciones arqueológicas en Cantabria, Anejos Archivo Español de Arqueología 4, Madrid.

Girón, L. y Costa, J. M. 2009: "La cerámica de imitación de engobe rojo pompeyano en los yacimientos militares romanos peninsulares. Un estado de la cuestión", Á. Morillo, N. Hanel y E. Martín (eds.), Limes XX. Estudios sobre la frontera romana / Roman Frontier Studies, Anejos de Gladius 9, Madrid, 497-512. 
Gómez-Pantoja, J. L. 1992: "La estación de Segisamo", Gerión 10, 259-274.

Gregory, I. N. 2003: A place in history: A guide to using GIS in historical research, Oxford.

Ingold, T. 1993: "The temporality of the Landscape", World Archaeology 25 (2), 152-174.

LaMotta, V. M. y Schiffer, M. B. 1999: "Formation process of household assemblages", P. Allison (ed.), The Archaeology of Household Activities, London, 19-28.

Lapuente, M. P., Pérez-Arantegui, J., Aguarod, C. y Alcorta, E. J. 1996: "Caracterización de imitaciones provinciales micáceas de engobe rojopompeyano en el norte de la Península Ibérica", Actes du colloque de Périgueux, Supplément à la Revue d'Archéometrie, Bordeaux, 89-94.

Llanos, A. 1974: "Urbanismo y arquitectura en poblados alaveses de la Edad del Hierro", Estudios de Arqueología Alavesa 6, 87-212.

López Monteagudo, G. 1998: Mosaicos romanos de Burgos, Corpus de Mosaicos de España XII, Madrid.

López Monteagudo, G. y Mañanes, T. 1993: "Mosaicos de León”, J. M. Blázquez, G. López Monteagudo, T. Mañanes y C. Fernández Ochoa, Mosaicos romanos de León y Asturias, Corpus de mosaicos de España X, Madrid, 11-42.

López Noriega, P. 1997: “Organización territorial romana en el conventus Cluniensis: algunas consideraciones sobre la creación de ciudades ex novo", Zephyrus 50, 217-224.

López Noriega, P. 1998: “Aproximación al proceso de urbanización en el norte de la península Ibérica: posibles creaciones de ciudades ex novo en el Conventus Cluniensis", Lancia 3, 191-204.

Marco, F., Perea, S. Ramírez Sádaba, J. L. y Salinas de Frías, M. 2008: "Cantabria en la vida y estructura administrativa, económica y militar del Imperio", J. R. Aja, M. Cisneros y J. L. Ramírez Sádaba (coords.), Los cántabros en la antigüedad. La historia frente al mito, Universidad de Cantabria, 169-189.

Miró, I y Canals, J. 1988: La producción de ánforas romanas en Catalunya. Un estudio sobre el comercio del vino de la Tarraconense (siglos I a.C.- I d.C.), British Archaeological Reports, Int. Series, 473, Oxford.

Montón, F. J. 1990: Las árulas de los conventos jurídicos caesaraugustano y tarraconense, Universidad de Zaragoza, Tesis doctoral inédita.

Montón, F. J. 1996: Las árulas de Tarraco, Tarragona.

Moreno, I. 2001: Descripción de la vía romana de Italia a Hispania en las provincias de Burgos y Palencia, Burgos.
Moreno, I. 2004: "Aqua Segisamonensis. El acueducto romano de Sasamón", Boletín de la Institución Fernán González 228, 27-56.

Morillo, A. 1991: "Fortificaciones campamentales de época romana en España", Archivo Español de Arqueología 64, 135-190.

Morillo, A. 1993: "Campamentos romanos en España a través de los textos clásicos", Espacio, Tiempo y Forma. Historia Antigua, serie II, 6, 379-397.

Morillo, A. 2000: "La legio IIII Macedonica en la Península Ibérica. El campamento de Herrera de Pisuerga (Palencia)", Y. Le Bohec y C. Wolff (eds.), Deuxième congrès de Lyon sur l'armée romaine: Les légions de Rome sous la Haut-Empire, II, Lyon, 609-624.

Morillo, A. 2011: "The Roman occupation in the North of Hispania: war, military deployment and cultural integration", G. Moosbauer y R. Wiegels (eds.), Fines imperii-imperium sine fine?, Osnabrücker Forschungen zu Altertum und AntikeRezeption 14, Rahden, 11-26.

Morillo, A., Perea, S. y Ramírez Sádaba, J. L. 2008: "Las guerras cántabras", J. R. Aja, M. Cisneros, y J. L. Ramírez Sádaba (coords.), Los cántabros en la antigüedad. La historia frente al mito, Santander, 101-131.

Neira, M. L. y Mañanes, T. 1998: Mosaicos romanos de Valladolid, Corpus de mosaicos de España XI, Madrid.

Núñez, S. y Curchin, L. A. 2005: "Corpus de ciudades romanas en el valle del Duero", M. Navarro y J. J. Palao (eds.), Villes et territoires dans le bassin du Douro á l'époque romaine: actes de la tableronde, Bordeaux, 429-612.

Orejas, A. 2002: "El territorio de las civitates peregrinas en los tratados de agrimensura. Las civitates del noroeste hispano", Habis 33, 389-406.

Orejas, A. y Ruiz del Árbol, M. 2008: “Territorio y dominio en las villas romanas: el fundus de Veranes", C. Fernández Ochoa, V. García-Entero y F. Gil Sendino (eds.), Las villae tardorromanas en el occidente del imperio: arquitectura y función. IV Coloquio Internacional de Arqueología en Gijón, Gijón, 167-192.

Palomino, A. L., Centeno, I. M. y Gonzalo, J. M. 2012: "Ciudad y territorio: patrones de poblamiento del Duero burgalés entre la época romana y la Alta Edad Media”, C. Fernández Ibáñez y R. Bohigas (eds.), In Durii Regione Romanitas. Estudios sobre la presencia romana en el valle del Duero en homenaje a Javier Cortés Álvarez de Miranda, Palencia, 295-303.

Parker, A. 1992: Ancient Shipwrecks of the Mediterranean and the Roman provinces, British Archaeological Reports Int. Series 580, Oxford. 
Peacock, D. P. S. 1977: "Roman amphorae: typology, fabric and origins", AA. VV., Méthodes classiques et methods formelles dans l'étude des amphores, Actes du colloque de Rome, Roma, 261-278.

Peacock, D. P. S. 1986: Amphorae and the Roman Economy: An Introductory Guide, London-New York.

Pensabene, P. 1999: Terracotte del Museo Nazionale Romano I. Gocciolati e protomi da sime, Roma.

Peña, T. J. 2007: Roman Pottery in the Archaeological Record, Cambridge.

Pérez Centeno, M. R. 1999: Ciudad y territorio en la Hispania del siglo III d.C., Valladolid.

Pérez González, C. 1983: “Cajitas celtibéricas de la provincia de Palencia: aportaciones, síntesis y localización", Publicaciones de la Institución Tello Téllez de Meneses 48, 5-27.

Pérez González, C. e Illarregui, E. 1990: "Las 1lamadas cajitas celtibéricas de época romana de Villabermudo", Actas del II Congreso de Historia de Palencia, I, Palencia, 297-317.

Pina Polo, F. 1993: “¿Existió una política romana de urbanización en el Nordeste de la Península Ibérica?", Habis 24, 77-94.

Pradales, D. y Gómez Santa Cruz, J. 2003: "La arqueología romana en la provincia de Burgos: orígenes y desarrollo (II)", Boletín de la Institución Fernán González 226, 61-85.
Pucci, C. 1975: "Cumanae testae", La Parola del Passato 30, 368-371.

Ramos, M. L. 1996: Las terracotas arquitectónicas en la Hispania romana: la tarraconense, Madrid.

Regueras, F. 2002: "Mosaico", M. T. Amaré (dir.), Astorga II. Escultura, glíptica y mosaico, León, 35-111.

Regueras, F. y Pérez Olmedo, E. 1997: Mosaicos romanos de Salamanca, Salamanca.

Ricciotti, D. 1978: Terracotte votive dell'Antiquarium Communale di Roma 1: Arule, Roma.

Rodríguez Colmenero, A. 1979: "Augusto e Hispania. Conquista y organización del Norte peninsular", Cuadernos de Arqueología de Deusto 7, 78-81.

Sacristán de Lama, J. D. 2007: La Edad del Hierro en la provincia de Burgos, Burgos.

Solana, J. M. 1976: Los turmogos durante la época romana, I. Las fuentes literarias, Valladolid.

Van Buren, E. D. 1918: "Terracotta arulae", Memoirs of the American Academy in Rome II, 15-53.

Vermeulen, F., Slapsak, B. y Mlekuz, D. 2013: "Surveying the Townscape of Roman Trea (Picenum)", P. Johnson y M. Millet (eds.), Archaeological Survey and the City, Oxford, 261-282.

VV. AA. 1996: Pompei. Abitare sotto il Vesuvio, Ferrara.

Recibido: 10-09-2013

Aceptado: 27-01-2014 